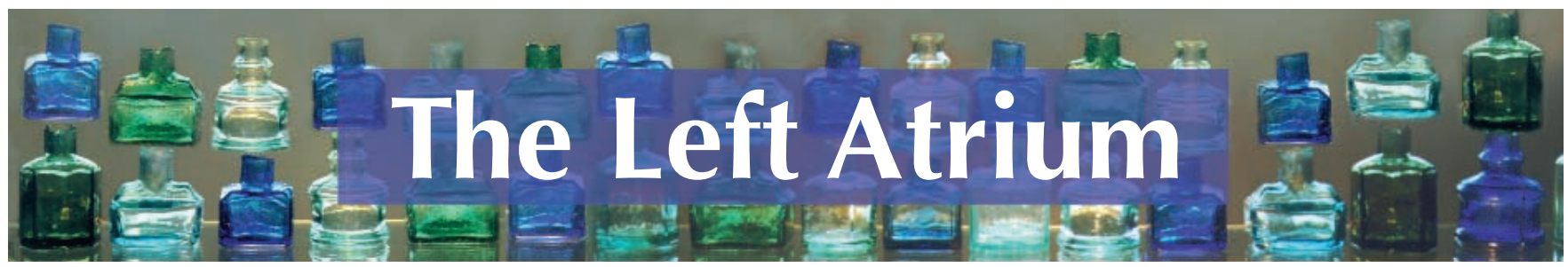

\section{Ethics and education}

The moral development of health care professionals Bertram Bandman

Westport (CT): Praeger; 2003

US\$69.95 pp. 208 ISBN 0-86569-259-9

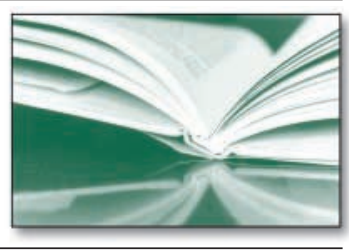

M ost if not all medical schools offer at least some introduction to the ethics of health care delivery. But there are skeptics who maintain that medical ethics courses are a waste of time, money and effort. One of the most well known articles on this subject was written by Michael Levin and appeared in 1989 in the New York Times. The article's title succinctly summarized the author's point of view: "Ethics Course - Useless." Simply, Levin postulated that "moral behavior is the product of training, not reflection." $\mathrm{Al}$ though Levin was not the first to express this opinion, his argument was well articulated and compelling.

Since this idea was first proposed, bioethicists, philosophers and other proponents of ethics courses have had to answer the skeptics' questions. A recent attempt, The Moral Development of Health Care Professionals, seeks to make a case for the teaching of health care ethics and to show that this teaching will lead to moral development. Bandman begins by looking at Levin's main argument, pointing out that training and reflection are not mutually exclusive. Citing many examples in support of this view, Bandman reasons that medical students can learn health care ethics through the twopronged approach of practical experience and didactic instruction.

Bandman poses several basic questions: Is there such a thing as moral development in health care? How does a professional develop morally? What are the factors that influence moral development? What is the role of rights and virtues in health care ethics? In seeking answers, he makes use of a number of interrelated methodologies, most notably "counterfactual conditional judgements."
A counterfactual conditional judgement takes the form of an "if-then" statement - that is, an antecedent "if clause" and a consequent "then clause." Bandman supports that controversial view that if the antecedent is to be considered to be true even when it is known to be false, then one can then attribute a value of true or false to the consequent to determine the overall validity of the statement. By relying mainly on this kind of reasoning, Bandman analyzes and presents an argument for each of the basic questions he has posed. However, the arguments he makes within this framework are not always well elucidated.

Bandman describes a range of hypotheses on moral development. These range from Lawrence Kohlberg's six stages of development to Gilbert Ryle's argument that the terms "moral" and "development" cannot coexist in the same context. Ryle believed that mental processes (including morality) cannot be reduced to the level of physical reality (stage-based development). He considered this to be a "category mistake," meaning that he did not believe that the mind developed in the same straightforward way as the body, through linear growth in stages. Bandman assumes otherwise, and argues that moral development is possible - but only when it is "justifiable." This notion of "justifiable" development, however, asks more questions than it answers.

Bandman describes several factors affecting moral development, including the concept of teaching and learning of values, the role of knowledge and the place for beliefs in health care, as well as the interplay between determinism and free will. These factors influence the different aspects or gears that make the health care system work in unison, from deliberation to justification to intervention, in a way that is accepted but hardly ever reflected on. As illustration, Bandman uses easy-to-understand examples taught in most medical ethics courses, such as Nazi practices and the infamous Tuskegee experiment in which 399 black American men suffering from syphilis were, without their knowledge, denied treatment so that the progress of their disease could be studied.

Bandman appeals to John Rawls' $A$ Theory of Fustice to justify the function and role of rights in health care ethics. By applying counterfactual conditional judgements, Bandman further explores three fundamental rights: the right to initiate life, the right to sustain life, and the right to end life. Medical students are taught about these rights as a means of attaining moral development. It follows, then, that to appreciate the role of rights in health care ethics, health care professionals should be taught the least rationally contestable and most justifiable of possible views. Bandman's quintessential example of this is that "if a woman were to carry a fetus after stage $\mathrm{L}$ and if the fetus after $\mathrm{L}$ were judged to be a person, then abortion after $\mathrm{L}$ would be murder, but not before L."

A weakness of this book is that it at times loses focus and jumps to conclusions. Although each chapter makes several valid points, the overall argument is not laid out in a logical manner and is therefore difficult to follow. For example, Bandman analyzes the role of "if" in the arts and shows how it is necessary to immerse ourselves in the imaginative world of a play, painting or piece of music to truly appreciate it. From this, Bandman draws a tenuous connection to the role that imagination must play in the moral development of health care professionals. In the very next paragraph, however, he invites us to consider Descartes' teachings more carefully, to doubt everything and to accept only ideas that are "clear 
and distinct." He concludes that a moral view is justified only if its values are grounded in fact and science.

Although this book in general would not serve as appropriate reading material for an undergraduate medical ethics course, its second chapter is an exception and would provide any physician or medical student with a concise history of virtue ethics and justifiable health care values. It eloquently summarizes the views of classical and modern philosophers ranging from Plato and Aristotle to Kant and Adam Smith. Overall, the book's heavy philosophical content and rich theories should at least provide several issues for debate among those interested in the ethical education of health care providers.

\section{Guy LeBlanc}

Medical Student

Dalhousie University

Halifax, NS

\section{Room for a view}

\section{Jerusalem life}

$I_{\mathrm{h}}^{\mathrm{h}}$ heard the sound of three sirens. When there are two sirens, one rising whine interweaves with the other, catches it, and intensifies the sound. Two sirens can be melodic, a children's two-part round bouncing off stone walls. Two sirens can mean two ambulances called by chance at the same time. Two sirens, if one has an interest in harmony or perhaps counterpoint, can be quite pleasant.

Three sirens, however, make the heart stop: it is the sound that comes after a suicide bombing. Jerusalem is too small a city to have three ambulances travelling at once, unless there has been a mass disaster. Three sirens are the herald. Sometimes you can hear the explosion itself; I did, once. I was hanging laundry on the veranda, squinting in the brightness of the Mediterranean sun ricocheting off white Jerusalem stone walls. Explosions can be many things, though: construction noises, backfiring cars, the fireworks set off at Arab weddings,

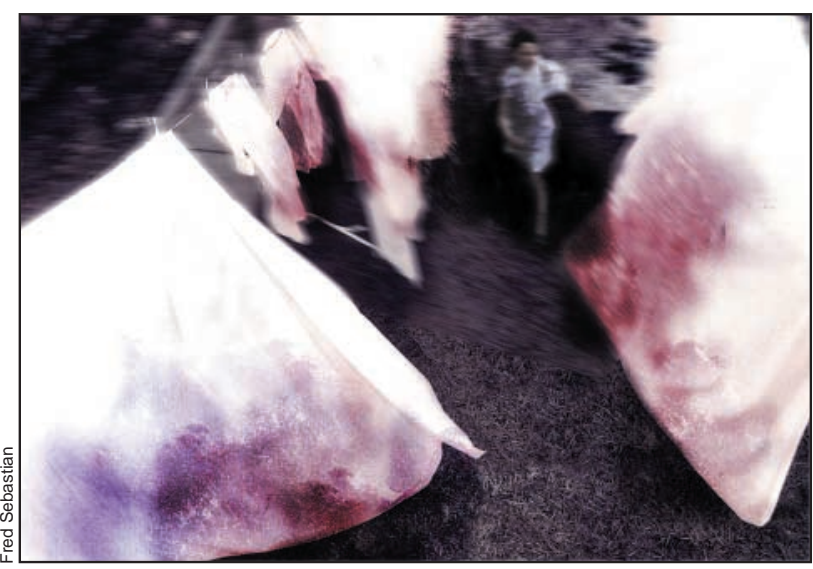

children playing with firecrackers. That time it was a bus bombing. I held my breath, waiting, while the sirens rose and fell. It was a terrible sound.

Between the bomb and the sirens, there is always an eerie, silent moment as everyone waits. Then comes the cacophony of cellphones. Für Elise starts, then Yankee Doodle, something from Riverdance, Hava Nagila. And the frantic voices: "Are you alright?" "Do you know which bus be was on?"

My first patient here in Jerusalem was involved in that bombing: thrown from the driver's seat, he landed on his back, stunned at first by the sound and later by all that he saw and felt. Did the suicide bomber know that a fellow Arab was driving the bus beside him? My patient had seen other physicians to treat the assault on his body: his bruised back, his diminished hearing, the whistling sounds that never ceased. He came to our psychiatry clinic, one might say, because he was suffering from an assault on his senses. The sights, the smells, the sounds and the sensations haunted him. Over and over he revisited the scene that had met him when he crawled from the bus: scattered body parts, rag-doll children. Worse, though, was the stench of burning bodies and the sickening feel of someone else's disembodied flesh flung upon him, which now would not let him be. All his senses were on fire.

In a Jerusalem besieged by terror not only physical sensations have intensified. Friends and family of victims have unearthed deep wells of kindness and heal their own pain by helping others. One couple, in response to the murder of their thirteen-year-old son, help siblings of terror victims rediscover joy. The dedicated young volunteers who run their camp programs were themselves inspired by the loss of friends. They have developed exquisite skill in dealing with bereaved families. With the bombings in their fourth year, however, some are beginning to feel out of their depth: "We know how to help families, even those who have lost more than one member in a single bombing. Now we are seeing the same families suffering more losses. We don't know how to comfort them."

Volunteers rush to join the Red Star of David, the Israeli counterpart of the Red Cross. Most paramedics here are volunteers. I meet with a new group of recruits, who are just beginning to learn resuscitation skills. They worry most about whether they will be competent; cautiously, they expose their uneasiness at the gruesome scenes they know they will have to face. Soon they will learn to cloak their fears in black humour.

My most recent patient can scarcely leave her house. She was once a confident young woman, but her imagination has been ignited by the explosion she and her family survived. She fears her children will be snatched from her home; the bars on the windows aren't strong enough. She cannot shower without her husband nearby, cannot 